\title{
Determination of Routine Vaccination Coverage Using Estimated and Survey Generated Population in Orhionmwon Local Government Area in South-South Nigeria
}

Ireye $\mathrm{F}^{1}$, Bassey Enya $\mathrm{B}^{1^{*}}$, Komakech $\mathbf{W}^{1}$, Okocha-Ejeko $\mathrm{A}^{1}$, Ali $\mathrm{D}^{1}$, Agwai SI1, Koko $\mathbf{R}^{1}$, Igbu $\mathrm{T}^{1}$, Maleghemi ST ${ }^{1}$, Adanini $\mathrm{J}^{2}$,Odia $\mathrm{P}^{3}$, Ejiyere HO${ }^{4}$ and Odiko

${ }^{1}$ World Health Organization (WHO), Nigeria Country Office, UN House, Diplomatic Drive, Central Business District, Garki, Abuja, Nigeria

${ }^{2}$ European Union Support to Immunization Governance in Nigeria, Benin City, Edo State, Nigeria

${ }^{3}$ Orhionmwon Local Government Area, Abudu, Edo State State, Nigeria

${ }^{4}$ Irrua Specialist Teaching Hospital, Irrua, Edo State, Nigeria

${ }^{5}$ Ministry of Health, Sapele, Road, Benin City, Edo State, Nigeria

*Corresponding author: Bassey EB, World Health Organization (WHO) Nigeria Country Office, UN House, Plot 617/618, Diplomatic Drive, Central Business District, PMB 2861, Garki, Abuja, Nigeria, Tel: 2340938003634; E-mail: bassey69@yahoo.com

Received date: August 04, 2017; Accepted date: August 12, 2017; Published date: August 21, 2017

Copyright: ( 2017 Ireye F, et al. This is an open-access article distributed under the terms of the Creative Commons Attribution License; which permits unrestricted use; distribution; and reproduction in any medium; provided the original author and source are credited.

\begin{abstract}
Background: The Expanded Program on Immunization (EPI) aims at delivering primary immunization services to at least $90 \%$ of infants. This study seeks to evaluate routine vaccination coverage using estimated and survey generated populations and also investigates the reasons for inadequate levels of routine vaccination coverage.
\end{abstract}

Method: A cross-sectional survey was conducted in all 11,101 households spread across 111 communities in the 12 administrative wards of Orhionmwon LGA of Edo state in October 2016.

Results: A total of 1209 children under the 0-11 month's age bracket had been fully immunized. From this figure, $72.9 \%$ of the children had been fully immunized based on the actual population (1657) of children as discovered from this survey while $12.5 \%$ of the children in the same aforementioned age bracket had been fully immunized based on the projected target population (9625).

Obstacles (40\%), 'lack of information (33\%)' and 'lack of motivation (27\%)'were the major reason why survey respondents didn't participate in routine immunizations.

Conclusion: Discrepancies in actual population of children for RI and poor access to RI services continue to negatively affect RI delivery mechanisms. We recommend the regular use of coverage surveys such as this for the estimation of actual target.

Keywords: Vaccination coverage; Target population; Edo state

\section{Introduction}

The prevention of mortality in children less than five years of age remains an area of key focus amongst policy makers both nationally and internationally. About three million children die globally from Vaccine Preventable Diseases (VPVs) each year. Approximately 1.5 million of such deaths occur in children under five years of age particularly in developing countries. This is why the Sustainable Development Goal's (SDG) target 3.2 and World Health Organization's (WHO) global strategy for mother and child care aims to reduce the mortality rate of children under the age of five to less than 25 children per 1000 live births in every country through improved Routine Immunisation (RI) services [1,2].

Guidelines from Nigeria's Expanded Programme on Immunization (EPI) states that one child should receive four doses of Oral Polio Vaccine (OPV), three doses of Hepatitis B, Diphtheria, pertussis, tetanus and Haemophilus influenza type $b$ vaccines, and one dose each of measles, Baccile Calmette-Guerin (BCG) and yellow fever vaccines by the age of one (year) [3,4]. Immunization with these vaccines is cost effective and by far the most widely applied public health intervention strategy for reducing childhood mortality [5-7].

However, inadequate levels of immunization continue to pose a major public health challenge especially in the rural areas of Nigeria despite efforts made by the EPI. The reasons for incomplete/partial immunization and factors responsible for missed opportunities as outlined in some studies have been mainly attributed to poor parental knowledge on immunization, parental neglect, domestic problems etc. $[7,8]$. However, little data is available to explain these challenges with recommendations that could support decision making for improved services.

The Investigation of the reasons for incomplete vaccination helps frame future policies that would improve RI delivery services and improve vaccination coverage [9]. This study seeks to evaluate routine vaccination coverage (using estimated and survey generated populations) and investigate the reasons for inadequate levels of 
Citation: Ireye F, Bassey EB, Komakech W, Okocha-Ejeko A, Ali D, et al. (2017) Determination of Routine Vaccination Coverage Using Estimated and Survey Generated Population in Orhionmwon Local Government Area in South-South Nigeria. J Infect Dis Med 2: 112. doi: $10.4172 / 2576-1420.1000112$

Page 2 of 5

routine vaccination coverage in Orhionmwon Local Government Area (LGA) Edo state, Nigeria.

\section{Methods}

\section{Study location}

This study was carried out in Orhionmwon LGA, Edo state, Nigeria. It has Abudu as its administrative headquarters. The LGA is divided into 12 administrative wards: Evboesi, Uronigbenorth, Uronigbe south, Abiokunla 1 and 2, Igbanke east, Igbanke west, Ugboko, Ugu, Ukpato, Iguododo, Iyoba and Ugbeka. Uhumwode and Esan West LGAs boarders this LGA to north, while by Ika south LGA, Ethiope east LGA and Ethiope west/Ukwani LGAs of Delta state boarders it to the east, south and west respectively.

The people in this LGA mostly belong to the Bini ethnic group. They are mostly framers, fishermen/women and traders.

\section{Study design}

A community based cross-sectional survey was conducted in all 11,101 households spread across 111 communities in the 12 administrative wards of Orhionmwon LGA of Edo state in October 2016.

\section{Sample size}

A total population assessment of 11,101 households with 6192 children under the age of five and 1657 children under the age of one were surveyed.

\section{Investigators/research assistants}

The data was collected through locally recruited trained data clerks. The inclusion criteria were mothers/caregivers with children between 0 to 59 months of age, residing in the area for at least 12 months prior to the study. Mothers or caregivers were sensitized and notified of the study through the Officer-in-charge of the various health facilities (HFs) offering RI in their locality.

\section{Data collection and analysis}

Information on the total number of households with children in the 0-59 months (0-5 year) age bracket in the LGA was obtained. The completeness and correctness of vaccination schedules were also checked using a standardized questionnaire.

Factors leading to missed opportunities or incompleteness of vaccination were also sought. Vaccination dates, number of doses and dates of visits to the HF were either extracted from the child's RI card or by taking vaccination history from the caregivers where RI card was absent. Information about child immunization history, mother or caregiver's knowledge on immunization and the National Program on Immunization (NPI) and factors affecting compliance with RI schedules were obtained through direct interview (oral interview) of the mothers/caregivers.

The standard measure of vaccination coverage is the percentage of children who have received the requisite number of vaccine doses irrespective of the age at which the vaccine was received [10]. However, to maximize protection against vaccine-preventable diseases, a child should receive all immunizations within recommended intervals [11].

\section{Ethical consideration}

Informed consents were obtained from the mothers after study objectives were explained. All respondents were free to withdraw from the study at any time without any consequence. The data were screened for inconsistencies and missing values. The collected data were entered into computerized database after coding using Microsoft excel and later converted to SPSS (version 20.0).

\section{Results}

Accurate data representing the actual number of children targeted for routine immunization is critical for the successful planning and improvement of vaccine administration in any given population. In this survey, all 11,101 households spread across 111 communities in the 12 administrative wards of Orhionmwon LGA of Edo state were visited (Table 1).

\begin{tabular}{|l|l|l|l|l|}
\hline Administrative wards & $\begin{array}{l}\text { Projected Target Population of } \\
\text { children aged 0-11 months }\end{array}$ & $\begin{array}{l}\text { Actual survey population of } \\
\text { children aged 0-11 months. } \\
(\%)\end{array}$ & $\begin{array}{l}\text { Projected target Population of } \\
\text { children aged 1-5 years }\end{array}$ & $\begin{array}{l}\text { Actual survey population } \\
\text { of children aged 1-5 years. } \\
\text { (\%) }\end{array}$ \\
\hline Abiokunla 1 and 2 & 1784 & $165(9.2)$ & 8588 & $436(5.1)$ \\
\hline Evboesi & 465 & $113(24.3)$ & 2312 & $505(21.8)$ \\
\hline Igbanke East & 497 & $58(11.6)$ & 3341 & $540(16.2)$ \\
\hline Igbanke West & 579 & $107(18.4)$ & 2893 & $489(16.9)$ \\
\hline Iguododo & 468 & $57(12.1)$ & 2304 & $252(10.9)$ \\
\hline Iyoba & 643 & $99(15.3)$ & 3215 & $195(6.1)$ \\
\hline Ugbeka & 972 & $109(11.2)$ & 4849 & $513(10.6)$ \\
\hline Ugboko & 1029 & $233(22.6)$ & 5145 & $769(14.9)$ \\
\hline Ugu & 1567 & $391(24.9)$ & 7836 & $946(12.1)$ \\
\hline Ukpato & 687 & $135(19.6)$ & 3439 & $733(21.3)$ \\
\hline
\end{tabular}


Citation: Ireye F, Bassey EB, Komakech W, Okocha-Ejeko A, Ali D, et al. (2017) Determination of Routine Vaccination Coverage Using Estimated and Survey Generated Population in Orhionmwon Local Government Area in South-South Nigeria. J Infect Dis Med 2: 112. doi:10.4172/2576-1420.1000112

Page 3 of 5

\begin{tabular}{|l|l|l|l|l|}
\hline Uronigbe North & 376 & $33(8.7)$ & 1881 & $80(4.3)$ \\
\hline Uronigbe South & 558 & $157(28.1)$ & 2791 & $734(26.3)$ \\
\hline Total & 9625 & $1657(17.2)$ & 45294 & $6192(13.7)$ \\
\hline
\end{tabular}

Table 1: Projected target population and actual survey population of children in the 0-11 months and 1-5 year age bracket in Orhionmwon LGA, Edo State, Nigeria.

In Table 1, the projected target population (based on the nationwide census of 2006) and actual survey population of children in the $0-11$ months and 1-5 years age bracket were illustrated. The actual survey population of children in the 0-11 months and 1-5 years age bracket were 1657 and 6192 children respectively in comparison to the 9625 and 45295 projected target population of children in the same respective age bracket (i.e., only $17.2 \%$ and $13.7 \%$ of the projected target population of children in the $0-11$ months and 1-5 years age groups are actually present in this LGA).

Abiokunla 1 and 2 was projected to have the highest population of children within the 0-11 months and 1-5 years age group (i.e., 1784 and 8588 children respectively). However, survey figures showed the actual population of the children in the same aforementioned age brackets to be $9.2 \%$ and $5.1 \%$ of their respective projected target populations. Uronigbe North was also projected to have the least population of children within the 0-11 months-age bracket (376) whereas survey figures indicate the presence only $8.7 \%$ of these children in the ward. This trend where projected target population exceed actual survey data was observed in all the wards except for Igbanke East where actual survey data for children in the 1-5 years' age bracket (540) actually exceeded the projected target population (41) for the children in the said age group.

RI levels were assessed next to ascertain the vaccination coverage of children in the 0-11 months' age bracket (Table 2).

\begin{tabular}{|l|l|l|l|l|}
\hline Ward & $\begin{array}{l}\text { Projected Target Population of } \\
\text { children aged 0-11 months }\end{array}$ & Fully immunized (\%) & $\begin{array}{l}\text { Actual survey population of } \\
\text { children aged 0-11 months }\end{array}$ & Fully immunized (\%) \\
\hline Abiokunla 1 and 2 & 1784 & $102(5.7)$ & 165 & $102(61.8)$ \\
\hline Evboesi & 465 & $86(18.5)$ & 113 & $86(76.1)$ \\
\hline Igbanke East & 497 & $58(11.7)$ & 58 & $58(100.0)$ \\
\hline Igbanke West & 579 & $89(15.4)$ & 107 & $89(83.2)$ \\
\hline Iguododo & 468 & $39(8.3)$ & 57 & $39(68.4)$ \\
\hline Iyoba & 643 & $88(13.7)$ & 99 & $88(88.9)$ \\
\hline Ugbeka & 972 & $45(4.6)$ & 109 & $45(41.3)$ \\
\hline Ugboko & 1029 & $192(18.7)$ & 233 & $192(82.4)$ \\
\hline Ugu & 1567 & $248(15.8)$ & 391 & $248(63.4)$ \\
\hline Ukpato & 687 & $96(14.0)$ & 135 & $96(71.1)$ \\
\hline Uronigbe North & 376 & $28(7.4)$ & 33 & $28(84.8)$ \\
\hline Uronigbe South & 558 & $138(24.7)$ & 157 & $138(87.9)$ \\
\hline Total & 9625 & $1209(12.6)$ & 1657 & $1209(72.9)$ \\
\hline
\end{tabular}

Table 2: Vaccination coverage based on the projected target population and actual survey population of children in the $0-11$ months age bracket in Orhionmwon LGA, Edo State, Nigeria.

A total of 1209 children under the 0-11 months' age bracket had been fully immunized. From this figure, $72.9 \%$ of the children had been fully immunized based on the actual population (1657) of children in the 0-11 months' age bracket as discovered from this survey while $12.5 \%$ of the children in the same aforementioned age bracket for this LGA had been fully immunized based on the projected target population (9625).
Vaccination shortfalls were experienced in all wards except for Igbanke East where the entire children in the ward had been fully immunized based on actual population data derived from this survey.

Reasons for these vaccination shortfalls were highlighted in Figures 1 and 2. From Figure 1, 'Obstacles (40\%)'were the major reason why survey respondents didn't participate in RI. This was closely followed by 'lack of information (33\%)' and 'lack of motivation' (27\%). 
Citation: Ireye F, Bassey EB, Komakech W, Okocha-Ejeko A, Ali D, et al. (2017) Determination of Routine Vaccination Coverage Using Estimated and Survey Generated Population in Orhionmwon Local Government Area in South-South Nigeria. J Infect Dis Med 2: 112. doi: $10.4172 / 2576-1420.1000112$

Page 4 of 5

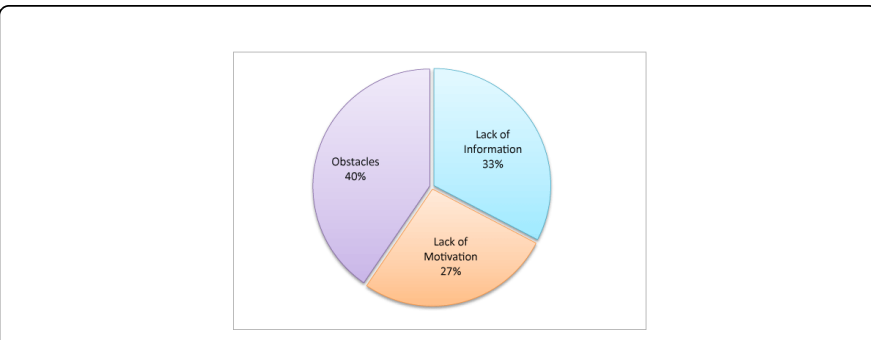

Figure 1: Reasons for low vaccination coverage in orhionmwon LGA, Edo State.

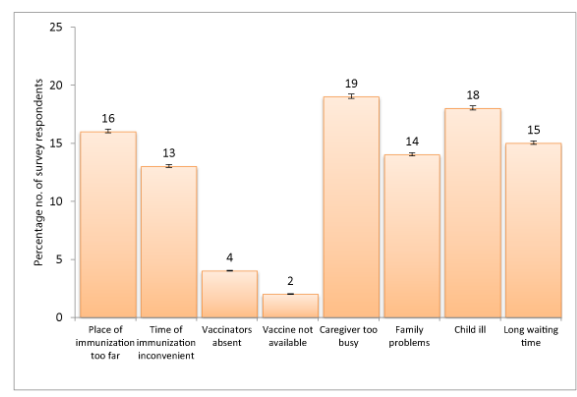

Figure 2: Estimates of the factors contributing vaccination shortfalls in orhionmwon LGA, Edo State.

Further analyses of the 'obstacles' preventing respondents from participating in RI were highlighted in Figure 2. About 19\%, 18\%, 16\%, and $15 \%$ of the respondents cited being busy, child/children ill, immunization place too far and long waiting time respectively as major obstacles preventing them from participating in RI. Note that the black vertical lines depict $95 \%$ confidence intervals (CI).

\section{Discussion}

Childhood immunization is no doubt one of the most important public health measures used to reduce the incidence of infectious diseases and save lives [12]. The vision of the EPI in Nigeria is to improve the health of Nigerian children through a highly sensitive RI system aimed at eradicating all eight killer diseases namely: poliomyelitis, measles, diphtheria, pertussis, hepatitis B, tuberculosis, tetanus and yellow fever.

However, Nigeria has witnessed a gradual but consistent decline in vaccination coverage since the early successes recorded by the EPI in the early 1990s. By 1996, Nigeria's national data showed a-less-than $30 \%$ coverage for all antigens, and this decreased to $12.9 \%$ in 2003 $[13,14]$. This figure, which is consistent with figures from the 2003 national immunization coverage survey, is among the lowest in the world and it explains the poor health status of children especially in the rural areas of the country [13]. Using Orhionmwon LGA Edo state, Nigeria as a case study, this study seeks to establish the major reasons for poor participation in RI and provide recommendations that would hopefully help improve the vaccination coverage in Nigeria.

All 11,101 households in Orhionmwon LGA were visited during this survey. A total of 1657 children within these households fell under the $0-11$ months age group and 6192 children fell within the 1-5 years age group. This was compared to the 9625 and 45,294 respective projected target population for children in the same aforementioned age group based on figures from the last national population census conducted in Nigeria in 2006 [15]. From these figures, it is obvious that a major discrepancy exist between the target population of the various administrative wards and the actual number of children that were captured in the course of the study. These high discrepancies exist probably because the figures being used as target population at HFs haven't been updated since the last population census of 2006. Also, a total of 1209 children under the $0-11$ months age bracket had been fully immunized but because of the discrepancies that exist between actual population and projected target population, immunization coverage (which is accessed based on the total number of fully immunized children in relation to the overall population), falls way below expectation as seen in the figures from Table 2 where immunization coverage based on projected target population was $12.5 \%$ while immunization coverage based on actual population was $72.9 \%$. It is important to stress on these inaccurate figures because policy makers, immunization services providers and stakeholder rely on national census figures to make decision concerning RI and distribution of resources to improve RI services. Incorrect data would lead to inaccurate estimation of vaccination coverage levels and attendant misjudgment in the deployment of healthcare personnel and healthcare resources. It is therefore imperative that concerted effort be made to address this gap both at the state and national levels through the State Primary Healthcare Development Agency and the National Primary Healthcare Development Agency in collaboration with National Population Commission to ensure the provision of accurate target population estimates to enable proper planning and implementation of vaccine administration strategies that would ultimately improve the vaccination coverage in country.

But this is not to say that there aren't other major factors affecting vaccination coverage. From this survey, vaccination shortfalls were observed in all wards except for Igbanke East where all the children in the $0-11$ months-age group had been fully immunized. The various reasons given by the mothers or caregivers for partial or nonvaccination of children were highlighted in Figures 1 and 2. 'Obstacles (40\%)' and 'lack of information (33\%)' on immunization activities were the major reasons why most of the children weren't fully immunized. This finding corresponds with that of a related study in Awe, LGA, in Nasarawa State (North-Central) where the same reasons were given for partial vaccination of the children 0-5 years age bracket. These findings highlight the need for targeted social mobilization strategies to increase compliance rates for RI by mothers/caregivers within the communities in the LGA. Upon further analyses of the 'obstacles' contributing to low immunization coverage, we discovered that: $19 \%$ of the caregivers were too busy to take their wards for immunization, $18 \%$ of them had their children ill at the time of immunization, $16 \%$ of the mothers felt that distance to the HF was too far, $15 \%$ of them were discouraged by the long waiting time before vaccine administration and $13 \%$ of the caregivers felt that the time slated for immunization was inconvenient. These findings were consistent with results from another survey concerning the routine immunization coverage in northern Nigeria [16].

This low reported use of RI services and the common identification of issues relating to access to RI services as a reason for nonvaccination (i.e., inconvenient location/time of vaccination etc.) suggest that more can be done to improve vaccine delivery mechanisms. Healthcare workers should endeavour to liaise with the mothers in the communities on the times convenient for RI and fix RI 
Citation: Ireye F, Bassey EB, Komakech W, Okocha-Ejeko A, Ali D, et al. (2017) Determination of Routine Vaccination Coverage Using Estimated and Survey Generated Population in Orhionmwon Local Government Area in South-South Nigeria. J Infect Dis Med 2: 112. doi: $10.4172 / 2576-1420.1000112$

Page 5 of 5

sessions accordingly. They should also ensure that these sessions start on time. Health workers should endeavour to maintain a good vaccination tracking system of the children vaccinated in the health facility to enable them effectively track defaulters, investigate their reasons for defaulting and respond accordingly.

This study had data analyses limitations. Exact figures for further analyses of each component under the 'obstacles' that prevented respondents form participating fully in RI was not available (missing) even when the exact total number of respondents that cited 'obstacles' as reason for partially immunizing their wards were present. This led to the generalized estimation of the proportion of respondents that could have chosen those components based on the total. Sampling error and $95 \%$ CI were then calculated as a result.

\section{Conclusion}

Discrepancies in actual population of children for RI and poor access to RI services continue to negatively affect RI delivery mechanisms. We recommend the regular use of coverage surveys such as this for the estimation of actual target population and as capacity building exercises for immunization staff, while incorporating the improved sampling methodology outlined in the recently updated WHO cluster survey guidelines to improve RI delivery and vaccination coverage [16].

\section{Competing Interests}

The Authors have none to declare.

\section{Funding}

This paper received no funding.

\section{References}

1. https://sustainabledevelopment.un.org/post2015/transformingourworld
2. http://www.who.int/life-course/partners/global-strategy/en/

3. http://www.who.int/immunization/documents/vaccination_coverage/en/ 4. http://www.who.int/mediacentre/factsheets/fs378/en/

5. Harris JB, Gacic-Dobo M, Eggers R, Brown DW, Sodha SV, et al. (2014) Global Routine Vaccination Coverage, 2013. MMWR 63: 1055-1058.

6. Tarantola D, Hacen M, Lwanga S, Clements CJ (2014) Annals of Vaccines and Immunization Is Immunization Coverage in Africa Slipping? An Evaluation of Regional Progress to 2013. Ann Vaccines Immun 1: 1007.

7. Nshimirimana D, Mihigo R, Clements CJ (2013) Routine Immunization Services in Africa: back to basics. J Vaccines Immun 1: 6-12.

8. Oyo-Ita A, Fakunle B, Fajola A, Edet E (2012) Immunization Coverage in Selected Communities in the Niger Delta, Nigeria. World J Vaccines 2: 21-26.

9. Sharma S, Kohli C, Sharma N, Mehra D (2016) Incomplete Immunization Coverage in Delhi: Reasons and Solutions. Primary Health Care 6: 1-3.

10. Luman ET, Barker LE, Shaw KM, McCauley MM, Buehler JW, et al. (2005) Timeliness of Childhood Vaccinations in the United States. JAMA 293: 1204.

11. Glauber JH (2003) The Immunization Delivery Effectiveness Assessment Score: A Better Immunization Measure? Pediatrics 112: e39-45.

12. Andre FB, Booy R, Bock HL, Clemens J, Datta SK, et al. (2011) Vaccination Greatly Reduces Disease, Disability, Death And Inequity Worldwide. Bulletin of the World Health Organization 86: 81-160.

13. Ophori EA, Tula MY, Azih AV, Okojie R, Ikpo PE (2014) Current Trends of Immunization in Nigeria: Prospect and Challenges. Trop Med Health 42: 67-75.

14. FBA Health Systems Analysts (2005) The State of Routine Immunization Services in Nigeria and Reasons for Current Problems.

15. Population Council (2007) Report of Nigeria's National Population Commission on the 2006 Census. Popul Dev Rev 33: 206-210.

16. Gunnala R, Ogbuanuet IU, Adegoke OJ, Scobie HM, Uba BV, et al. (2016) Routine Vaccination Coverage in Northern Nigeria: Results from 40 District-Level Cluster Surveys, 2014-2015. PLoS One 11: e0167835. 